\title{
Effects of pentagamavunon-0 (PGV-0) as alternative analgesics on orthodontic tooth movement in rats
}

\author{
Cendrawasih Andusyana Farmasyanti ${ }^{1 *}$, Anne Marie Kuijpers-Jagtman², Heni \\ Susilowati ${ }^{3}$, Edy Meiyanto ${ }^{4}$ \\ ${ }^{1}$ Dentistry Doctoral Program, Faculty of Dentistry Gadjah Mada University, Indonesia \\ ${ }^{2}$ Department of Orthodontics and Craniofacial Biology, Faculty of Dentistry Radboud University, \\ Netherlands \\ ${ }^{3}$ Department of Oral Biology, Faculty of Dentistry Gadjah Mada University, Indonesia \\ ${ }^{4}$ Department of Pharmaceutical Chemistry, Faculty of Pharmacy Gadjah Mada University, Indonesia
}

\begin{abstract}
Introduction: Some analgesic drugs may have adverse effects on bone remodelling and, thus, on orthodontic tooth movement rate (OTM). GV-0 is synthesized by reacting vanillin and cyclopentanone catalyzed in acidic condition, and it has been revealed as a selective COX-2 inhibitor. This study was aimed to investigate the effect of pentagamavunon-0 (PGV-0), one of the curcumin analogues, on OTM. Methods: This study was conducted on 50 male Wistar rats $(350-450 \mathrm{~g})$ which were randomly divided into five groups ( $n=10$ each): 1) no treatment group (NT), 2) orthodontic treatment only (ORT), 3) ORT plus $0.4 \%$ sodium carboxymethyl cellulose ( $\mathrm{Na}-\mathrm{CMC}$ ) analgesic carrier, 4) ORT plus $200 \mathrm{mg} / \mathrm{kg}$ BW Paracetamol (PCT) as the positive control, and 5) ORT plus PGV-0 (50 mg/kg BW (PGV-0). Results: Drug and day interaction was statistically significant on two-way ANOVA. Post-hoc analyses showed that OTM increased from day 3 to 7 in all orthodontic groups over the same distance ( $p>0.05)$. Maximum OTM was found on day 6 , which was significantly farther than the distance on day 4. On day 7, OTM was less than on day 6 . OTM in all orthodontic groups, including in the PGV-0 group, was higher than in the NT group $(p<0.05)$. No differences was seen in OTM between PGV-0 group and other orthodontic groups $(p>0.05)$. Post-hoc analysis (intra days) revealed that OTM in PGV-O and other orthodontic treatment groups increased. Conclusion: After a single orthodontic force, PGV-0 does not inhibit tooth movement in rats from day 1 to day 7. Therefore, it is possible to develop PGV-0 as an alternative analgesics during orthodontic therapy.
\end{abstract}

Keywords: Analgesic drug, orthodontics, tooth movement, curcumin.

p-ISSN: 1979-0201; e-ISSN: 2549-6212; Available from: http://jurnal.unpad.ac.id/pjd/article/view/20995

DOI: 10.24198/pjd.vol31no3.20995

Submission: Feb 26, 2019; Accepted: Nov 14, 2019; Published online: Nov 30, 2019

"Corresponding author: Dentistry Doctoral Program, Faculty of Dentistry Gadjah Mada University, Indonesia. Denta 1, Sekip Utara, Yogyakarta, Special Region of Yogyakarta, Indonesia, 55281. Phone: +628995004600; Email: cendrawasih@ugm. ac.id 


\section{INTRODUCTION}

Orthodontic pain occurs due to the release of inflammatory mediators, especially prostaglandin, that stimulates the nerve endings around the teeth and their supporting tissues..$^{1,2}$

In bone remodelling, osteoclasts will resorb the bone at the direction of the force and deposit osteoblasts at the tension site, thus enabling the tooth to move. ${ }^{3,4}$ The differentiation process of osteoclasts and osteoblasts occurs in a harmonious orchestra of induction mechanisms between periodontal ligament (PDL) cells, bone cells, and physical or chemical stimulus factors such as cytokines and growth factors. Of all mechanisms involved, the arachidonic acid cascade is the most predominant process as it produces prostaglandin, particularly prostaglandin E2 (PGE2). ${ }^{1,2}$

When cell homeostasis is disrupted, the arachidonic cascade will be induced by enzymes, degrading the membrane-bound phospholipids into arachidonic fatty acids. Cyclooxygenase (COX) converts the arachidonic acid into unstable cyclic endoperoxides from which prostaglandins, one of the prostanoids besides prostacyclins and thromboxanes, are derived. ${ }^{5,6}$ This COX pathway can make use of Cyclooxygenase-1 (COX-1) for the process in the body, Cyclooxygenase-2 (COX -2) which emerges in inflammatory processes, or Cyclooxygenase-3 (COX-3) as the derivatives of COX-1, which is mostly found in the brain. ${ }^{7,8}$

Non-Steroids Anti Inflammatory Drugs (NSAIDs) are analgesics that are often used to relieve pain by blocking the COX pathway. ${ }^{9,10}$ The inhibition of prostaglandin production through the COX-2 pathway is known to cause inhibition of orthodontic tooth movement."11 Orthodontic pain can occur for 2-4 days after every activation of the orthodontic appliance. ${ }^{12}$ The search for analgesics that do not cause adverse effects, such as inhibition of the remodelling process, and can guarantee a safe and repetitive use during orthodontic treatment which takes an average of 2 to 3 years, is essential.

Paracetamol (Figure 1C) works through COX-2 and does not inhibit the tooth movement in vivo ${ }^{11}$; however, it has hepatotoxic side effects. ${ }^{13}$ Pentagamavunone-0(2,5-bis-(4'-hydroxy-3'methoxybenzylidine cyclopentanone) (PGV-0) is one of the curcumin analogs ${ }^{14}$ (Figure 1A and 1B) and it is the active molecule of the curry spice turmeric. ${ }^{15}$ PGV-0 is synthesized by reacting vanillin and cyclopentanone catalyzed in acidic condition. ${ }^{16}$<smiles>COc1cc(/C=C/C(=O)CC(=O)/C=C/c2ccc(O)c(OC)c2)ccc1O</smiles><smiles>COc1cc(/C=C2\CC/C(=C\c3ccc(O)c(OC)c3)C2=O)ccc1O</smiles>

Figure 1.A) Curcumin ((1E,6E)-1-(4-hydroxy-3methoxyphenyl)-7-(3- methoxy-4-methylphenyl) hepta1,6-diene-3,5-dione); B) PGV-0 ((2E,5E) -2- [(4-hydroxy3-methoxyphenyl) methylidene] -5- [ (3- methoxy4-methylphenyl ) methylidene] cyclopentan-1- one); C) Paracetamol (N-acetyl-para-aminphenol)

This analog works through COX-2 and is known to have a higher analgesic effect than paracetamo ${ }^{17}$ without causing side effects due to its high antioxidant properties. ${ }^{18}$ This study was aimed to analyze the effects of PGV-0 on orthodontic tooth movement from day 1 to day 7 after orthodontic force application in rats.

\section{METHODS}

This experimental study was conducted on 50 male Wistar rats (350-450 g) and has been approved ethical aspects of experimental research with experimental animals by the Ethical Committee of the Faculty of Dentistry of Gadjah Mada University, Indonesia: 009977/KKEP/FKG-UGM/ $E C / 2017$. A metal band was cemented on each incisor of the rats. A force of $35 \mathrm{cN}$ was applied using a 0.012 -inch stainless steel coil spring (Ortho Prime Inc. USA; AW 85021201; orthoshape SS $0.012 ")$ to separate the two upper incisors. 
The animals were randomly grouped into 5 groups ( $n=10$ each): 1) without treatment group (NT), 2 ) orthodontics only (ORT), 3) orthodontics with $0.4 \%$ sodium carboxymethyl cellulose ( $\mathrm{Na}-\mathrm{CMC}$ ) analgesic carrier, 4) orthodontics with $200 \mathrm{mg} / \mathrm{kg}$ BW Paracetamol (PCT) and 5) orthodontics with (50mg/kg BW PGV-0 (PGV-0).

All drugs were given orally one hour before the start of the OTM and every 12 hours for seven days. OTM was measured daily at the same time using digital sliding callipers (Mitutoyo, Japan). Every measurement was done twice with a 10 minutes interval in three repetitions by an observer. OTM was consistently measured between the incisors at the same point of the uppermost mesial side of the metal band around each incisor. OTM values were calculated by subtracting the distance measured on day 0 from a distance measured at each examination day.

All statistical analyses were performed using SPSS version 22 (Chicago, IL, USA). Means and standard deviations for OTM were calculated in mms. The reliability coefficients between the two measurements taken by one observer were calculated as Pearson's correlation coefficients. The duplicate measurement error (DME) was calculated as the SD of the difference between the two observations divided by $\sqrt{2}$. Paired sample t-tests were applied to identify the systematic differences between the first and second measurements.

The effect of drugs and day of the examination, as well as the interaction of the two variables were analyzed using two-way ANOVA. The comparisons of OTM between the two drugs and on each examination day were analyzed using one-way ANOVA. The significance level $=p<0.05$.

\section{RESULTS}

\section{Error of the methods}

Pearson's correlation coefficients for the intraobserver reliability ranged from 0.091 to 0.993 , with the lowest for the NT group (Table 1). The duplicate measurement error (DME) was small and varied from 0.045 to $0.298 \mathrm{~mm}$. The mean differences between the first and second measurement were very small. There was only one significant difference between the first and second measurement (PGV-0 on day 5).

\section{Orthodontic tooth movement}

During the experiment, one rat died in the $\mathrm{Na}$ CMC, PCT, and PGV-0 groups, respectively. Table

Table 1. Intra-observer performance for measurement of interincisor distance

\begin{tabular}{|c|c|c|c|c|c|}
\hline & & Reliabilty & DME & Mean diff. & P-value \\
\hline \multirow[t]{5}{*}{ Day 0} & NT & 0.266 & 0.156 & -0.066 & 0.366 \\
\hline & ORT & 0.880 & 0.115 & -0.077 & 0.165 \\
\hline & $\mathrm{Na}-\mathrm{CMC}$ & 0.588 & 0.152 & -0.006 & 0.934 \\
\hline & PCT & 0.591 & 0.201 & -0.060 & 0.520 \\
\hline & PGV-0 & 0.604 & 0.150 & -0.083 & 0.246 \\
\hline \multirow[t]{5}{*}{ Day 1} & NT & 0.491 & 0.153 & 0.030 & 0.670 \\
\hline & ORT & 0.856 & 0.155 & -0.018 & 0.801 \\
\hline & $\mathrm{Na}-\mathrm{CMC}$ & 0.922 & 0.111 & 0.022 & 0.663 \\
\hline & PCT & 0.963 & 0.085 & -0.061 & 0.140 \\
\hline & PGV-0 & 0.873 & 0.137 & -0.008 & 0.894 \\
\hline \multirow[t]{5}{*}{ Day 2} & NT & 0.601 & 0.131 & 0.086 & 0.177 \\
\hline & ORT & 0.868 & 0.168 & -0.092 & 0.251 \\
\hline & $\mathrm{Na}-\mathrm{CMC}$ & 0.953 & 0.119 & -0.064 & 0.286 \\
\hline & PCT & 0.957 & 0.096 & -0.034 & 0.448 \\
\hline & PGV-0 & 0.903 & 0.155 & -0.046 & 0.547 \\
\hline \multirow[t]{5}{*}{ Day 3} & NT & 0.259 & 0.121 & -0.051 & 0.371 \\
\hline & ORT & 0.975 & 0.099 & -0.030 & 0.516 \\
\hline & $\mathrm{Na}-\mathrm{CMC}$ & 0.993 & 0.097 & -0.062 & 0.210 \\
\hline & PCT & 0.932 & 0.156 & -0.062 & 0.400 \\
\hline & PGV-0 & 0.964 & 0.085 & 0.022 & 0.590 \\
\hline \multirow[t]{5}{*}{ Day 4} & NT & 0.232 & 0.170 & -0.091 & 0.263 \\
\hline & ORT & 0.984 & 0.045 & -0.013 & 0.543 \\
\hline & $\mathrm{Na}-\mathrm{CMC}$ & 0.977 & 0.113 & 0.023 & 0.674 \\
\hline & PCT & 0.576 & 0.263 & 0.103 & 0.406 \\
\hline & PGV-0 & 0.844 & 0.163 & -0.074 & 0.361 \\
\hline \multirow[t]{5}{*}{ Day 5} & NT & 0.735 & 0.071 & 0.026 & 0.425 \\
\hline & ORT & 0.886 & 0.172 & 0.139 & 0.104 \\
\hline & $\mathrm{Na}-\mathrm{CMC}$ & 0.851 & 0.223 & 0.022 & 0.838 \\
\hline & $\mathrm{PCT}$ & 0.571 & 0.248 & -0.032 & 0.782 \\
\hline & PGV-0 & 0.762 & 0.163 & -0.213 & 0.024 \\
\hline \multirow[t]{5}{*}{ Day 6} & NT & 0.091 & 0.094 & -0.090 & 0.061 \\
\hline & ORT & 0.651 & 0.179 & -0.099 & 0.247 \\
\hline & $\mathrm{Na}-\mathrm{CMC}$ & 0.947 & 0.076 & -0.065 & 0.108 \\
\hline & PCT & 0.699 & 0.148 & -0.070 & 0.343 \\
\hline & PGV-0 & 0.522 & 0.202 & 0.079 & 0.429 \\
\hline \multirow[t]{5}{*}{ Day 7} & NT & 0.031 & 0.174 & 0.062 & 0.444 \\
\hline & ORT & 0.762 & 0.216 & 0.001 & 0.996 \\
\hline & $\mathrm{Na}-\mathrm{CMC}$ & 0.975 & 0.061 & 0.043 & 0.175 \\
\hline & PCT & 0.203 & 0.298 & -0.003 & 0.983 \\
\hline & PGV-0 & 0.900 & 0.097 & -0.103 & 0.055 \\
\hline
\end{tabular}

NT: no treatment; ORT: Orthodontics only; Na-CMC: orthodontics plus drug carrier group; $\mathrm{PCT}$ : orthodontics plus Paracetamol; PGV-0: orthodontics plus PGV-0. 


\begin{tabular}{|c|c|c|c|c|c|c|c|c|c|c|c|c|c|c|c|}
\hline \multirow[b]{2}{*}{ Day 1} & \multicolumn{3}{|c|}{$\mathrm{NT} \pm \mathrm{SD}$} & \multicolumn{3}{|c|}{$\mathrm{ORT} \pm \mathrm{SD}$} & \multicolumn{3}{|c|}{$\mathrm{Na}-\mathrm{CMC} \pm \mathrm{SD}$} & \multicolumn{3}{|c|}{$\mathrm{PCT} \pm \mathrm{SD}$} & \multicolumn{3}{|c|}{$P G V-0 \pm S D$} \\
\hline & 0.08 & \pm & 0.15 & 0.32 & \pm & 0.25 & 0.18 & \pm & 0.25 & 0.12 & \pm & 0.43 & 0.14 & \pm & 0.28 \\
\hline Day 2 & -0.01 & \pm & 0.20 & 0.27 & \pm & 0.41 & 0.28 & \pm & 0.35 & 0.37 & \pm & 0.32 & 0.45 & \pm & 0.31 \\
\hline Day 3 & 0.12 & \pm & 0.13 & 0.62 & \pm & 0.52 & 0.72 & \pm & 0.48 & 0.54 & \pm & 0.44 & 0.48 & \pm & 0.31 \\
\hline Day 4 & 0.39 & \pm & 0.19 & 0.34 & \pm & 0.44 & 0.46 & \pm & 0.35 & 0.37 & \pm & 0.40 & 0.67 & \pm & 0.36 \\
\hline Day 5 & 0.23 & \pm & 0.19 & 0.62 & \pm & 0.33 & 0.58 & \pm & 0.52 & 0.59 & \pm & 0.25 & 0.72 & \pm & 0.28 \\
\hline Day 6 & 0.08 & \pm & 0.14 & 0.7 & \pm & 0.47 & 0.72 & \pm & 0.36 & 0.72 & \pm & 0.27 & 0.86 & \pm & 0.28 \\
\hline Day 7 & 0.00 & \pm & 0.14 & 0.55 & \pm & 0.63 & 0.51 & \pm & 0.24 & 0.72 & \pm & 0.40 & 0.73 & \pm & 0.37 \\
\hline
\end{tabular}

Notes: Mean \pm Standard Deviation are given in $\mathrm{mm}$. OTM values were calculated by subtracting the distance measured at day 0 from the distance at the specific examination day. Values are presented as mean \pm standard deviation. NT: no treatment; ORT: Orthodontics only; Na-CMC: orthodontics plus drug carrier group; PCT: orthodontics plus Paracetamol; PGV-0: orthodontics plus PGV-0.

2 presents the mean and SD of OTM during the experimental period, starting from day 1 to day 7. All data were normally and homogeneously distributed $(p>0.05)$.

After seven days of force application, the OTM varied between 0.55 (SD 0.63) and 0.73 (SD 0.37) $\mathrm{mm}$ in the experimental groups, while virtually, no movement was seen in the NT group.

Figure 2 depicts the OTM from day 1 to day 7 in the experimental groups and in the control group. OTM distance in the PGV-0 group increased, as also seen in other experimental groups. Statistical analyses showed no significant differences for the OTM between PGV-O and other orthodontic groups. OTM between some of the measurement days was significantly different, as presented in Table 3, however, there was no significant difference seen for the OTM between all orthodontic groups on a certain day, which is presented in Table 4.

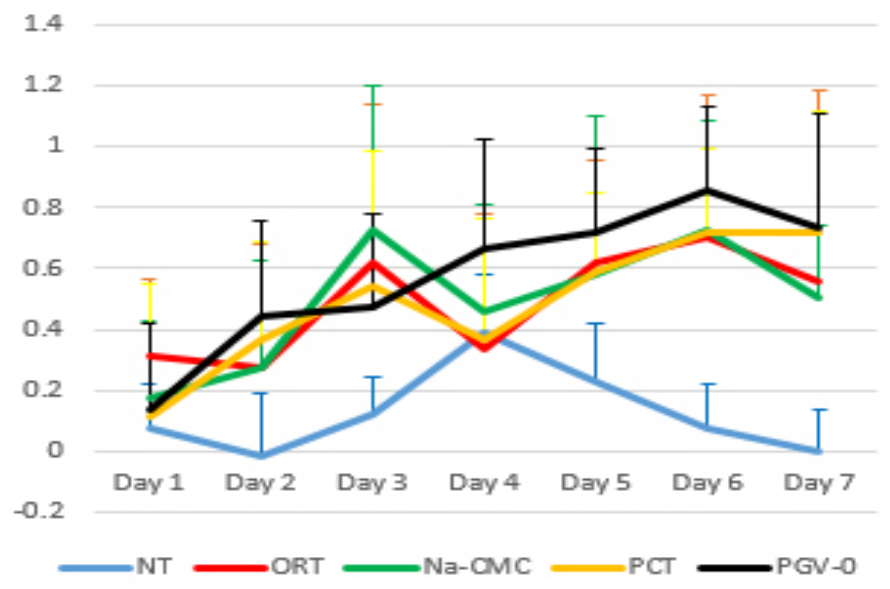

Figure 2. OTM (in $\mathrm{mm}$ ) from day 1 to day 7 after a single orthodontic force. NT: no treatment; ORT: Orthodontics only; NaCMC: orthodontics plus drug carrier group; PCT: orthodontics plus Paracetamol; PGV-0: orthodontics plus PGV-0; Statistical analysis showed that OTM was the same for all orthodontic groups from day 1 to day 7 . PGV-0 and control groups were not significantly different inter- or intra-days. There was an interaction between the day of examination and drugs factors $(p<$ 0.05). Post-hoc comparison of one- and two-way ANOVA can be seen in Table 3 and 4.

Two-way ANOVA showed a significant difference between days of examination and between drug groups, as well as a significant interaction between both factors. The following post-hoc comparison between days revealed that OTM started to increase significantly on day 3 . The OTM distance on day 2 was significantly different from the OTM distance on day 3, 4, 5, 6, and 7 with no significant movement from day 3 to day 7 . On day 6, the OTM distance was significantly larger than on day 4. Post-hoc comparison between PGV0 and all other groups showed that the OTM was larger than in the NT group, albeit insignificant ( $p$ $>0.05$ ). 
One-way ANOVA and post-hoc test results showed that the majority of the daily OTM of all orthodontic groups was significantly larger than in the control group except for day 1 and day 4 (p $>0.05$ ). Still, no significant differences was seen between the orthodontic groups (Table 3 and 4 ).

Table 3. Two-way ANOVA and post hoc test on the effect of PGV-0 on OTM from day 1 to day 7.

\begin{tabular}{|c|c|c|}
\hline Two-way ANOVA & P-value & Post hoc (LSD) \\
\hline Drugs & $<0.001$ & $\mathrm{ORT}^{*}, \mathrm{Na}-\mathrm{CMC}^{*}, \mathrm{PCT}^{*}, \mathrm{PGV}-0^{*}$ \\
\hline Day & $<0.001$ & $\begin{array}{l}\text { Day } 3^{* *} \text {, Day } 4^{* *} \text {, Day } 5^{* *} \text {, Day } \\
6^{* *} \text {, Day } 7^{* *} \\
\text { Day } 3^{* * *} \text {, Day } 4^{* * *} \text {, Day } 5^{* * *} \text {, } \\
\text { Day } 6^{* * *} \text {, Day } 7^{* * *} \\
\text { Day } 6^{* * * *}\end{array}$ \\
\hline Drugs $x$ * Day & 0.025 & \\
\hline
\end{tabular}

Notes: OTM values were calculated by subtracting the distance measured at day 0 from the distance at a certain examination day. ${ }^{a}$ Tested by two-way analysis of variance, and post-hoc LSD analysis test; NT: no treatment; ORT: Orthodontics only; Na-CMC: orthodontics plus drug carrier group; PCT: orthodontics plus Paracetamol; PGV0 : orthodontics plus PGV-0; *significantly higher than NT $(p<0.05)$; **significantly higher than day $1(p<0.05)$; ${ }^{* * *}$ significantly higher than day $2(p<0.05) ;{ }^{* * * *}$ significantly higher than day $4(p<0.05)$

Table 4. One-way ANOVA and post hoc test on the effect of PGV-0 in day 1 until day 7 on OTM.

\begin{tabular}{ccc}
\hline & $\begin{array}{c}\text { One-way ANOVA } \\
\text { (P value) }\end{array}$ & \multicolumn{1}{c}{$\begin{array}{c}\text { Post hoc (LSD) } \\
(\mathrm{P} \text { value) }\end{array}$} \\
\hline Day 1 & 0.535 & - \\
Day 2 & 0.004 & $($ ORT, NA-CMC, PCT, PGV-0) \\
Day 3 & 0.003 & $($ ORT, NA-CMC, PCT, PGV-0) \\
Day 4 & 0.153 & \\
Day 5 & 0.003 & $($ ORT, NA-CMC, PCT, PGV-0) \\
Day 6 & $<0.001$ & $($ ORT, NA-CMC, PCT, PGV-0) \\
Day 7 & $<0.001$ & (ORT, NA-CMC, PCT, PGV-0) \\
\hline
\end{tabular}

Note: OTM values were calculated by subtracting the distance measured at day 0 from the distance at a certain examination date. Tested by one-way analysis of variance, and post-hoc LSD analysis test; NT: no treatment; ORT: Orthodontics only; Na-CMC: orthodontics plus drug carrier group; PCT: orthodontics plus Paracetamol; PGV-0: orthodontics plus PGV-0; *significantly higher than NT ( $p<$ $0.05)$, no differences between drugs $(p>0.05)$

\section{DISCUSSION}

Forces created during orthodontic treatments induce the inflammatory mediators, in particular prostaglandins, which in turn stimulates remodeling process, osteoclastic resorption at the pressure side, and osteoblastic apposition on the tension side to move the tooth. ${ }^{1}$ However, prostaglandin also stimulates the nerve endings around the teeth and supporting tissues, triggering pain after force application. Non-steroidal Anti-Inflammatory Drugs (NSAIDs) are used to relieve the pain by blocking the cyclooxygenase (COX) pathway of prostaglandin COX-2 synthesis. ${ }^{11}$ Inhibition of prostaglandin production, however, may impede orthodontic tooth movement. ${ }^{11}$ Paracetamol does not hamper orthodontic tooth movement (OTM) in vivo, ${ }^{11}$ but it has a hepatotoxic side effect. An alternative for paracetamol could be PGV-0, which is an active compound of curcumin analog. This analog is known to have a higher analgesic effect than paracetamol without causing adverse effects. This study analyzed the effect of a new curcumin analog, PGV-0, on OTM in comparison to paracetamol as a positive control. PGV- 0 has been proven to have a higher analgesic potential than paracetamol, without triggering any side effect such as hepatoxic effects or ulcer digastricus. ${ }^{15}$ With regards to orthodontic therapy, the side effects of a certain medication used for pain relief are important because of the long duration of orthodontic therapy. PGV-0 has been known to take its action via COX-2, which is the same as paracetamol.

This study was performed on rats that received a custom-made spring to move the incisors. The spring had not achieved its initial width activation, which could be seen from the activation results at the end of the experiment. The force characteristics of this spring were tested in mice by a previous group. ${ }^{19}$ They found that the initial force exerted by the spring at maximum opening $(3.5 \mathrm{~mm})$ only showed a minor decrease after constriction to $3.2 \mathrm{~mm}$ over a 12day period. Thus, the force was nearly constant over this period, which fits well with the length of our experimental period. ${ }^{19}$

As presented in Figure 1, the OTM distance generally increased and all orthodontic groups showed the same pattern over a period of 7 days. Two-way ANOVA showed some significant differences in OTM between days. Post-hoc analyses showed no significant differences in OTM between day 1 and day 2 . This is in line with the literature stating that the first phase of OTM, that lasts approximately 24 hours to 
two days, in which the teeth are moved in their socket only. At the pressure side, the width of the periodontal ligament will be reduced due to the force application and an instantaneous movement of the tooth followed by a slowing down of OTM, probably due to hyalinization of the periodontal ligament. ${ }^{20-22}$

Thereafter, OTM increased significantly from day 3 on. The amount of OTM was significantly different between day 2 and all other days (day $3,4,5,6$, and day 7 ), but OTM from day 3 to day 7 was not significantly different from each other $(p>0.05)$. There was a trend of decreasing OTM from day 6 to day 7, but this was not significant. Only the OTM on day 6 was significantly higher $(p<0.05)$ in comparison to day 4. Orthodontic tooth movement is characterized by 4 phases: the initial strain phase, the lag phase, accelerated tooth movement phase, and, finally, constant linear tooth movement phase. ${ }^{23}$ The lag phase with tooth movement arrest ends after the removal of necrotic tissue, which has been described as occurring between 7 and 21 days in dogs. ${ }^{24}$ The necrotic areas in rats are shorter due to its narrower PDL width so it is more prone to force, diminished blood flow, and faster necrotic area induction. This might mean that the OTM in our experiment was probably still in the arrest phase, based on the assumption that the removal of necrotic tissue was in progress.

In an OTM study, prostaglandin-2 (PGE2) levels peaked at $24 \mathrm{~h}$ and decreased on day 7 to baseline levels where the orthodontic force decay likely accounted for the decrease in the PGE2 level. ${ }^{25}$ The tooth movement on day 7 of our study decreased slightly; however, the value was still higher than on day 2 and the OTM was still the same as on day $3(p>0.05)$. Though the drugs were given continuously from one hour before the orthodontic force was applied and twice a day for 7 days, PGE2 seemed still to be produced. All OTM distances had increased significantly until day 7 . This means that OTM was not influenced by the type of drug. The significant interaction between day and drugs suggested that the OTM was not only induced by orthodontic force but also by the drugs.

PGV-0 and Paracetamol seemed to stimulate OTM more even though they were not significantly different with OTM in ORT. In studies on COX-
2, selective inhibitors NSAIDs has the ability to harm or to postpone bone healing or lessen bone mechanical integrity. ${ }^{5}$ In studies on the effect of NSAIDs on bone cells, COX-2 selective inhibitors do not only impair the osteoclast ${ }^{26}$, but also the osteoblast.

In a study that was conducted on women aged $\geq 50$ year, paracetamol use has been associated with a $56 \%$ increase in fracture risk due to its mechanism of action to bone metabolism. ${ }^{27}$ Paracetamol has been known to act via COX-2, just like other NSAIDs. In some circumstances, such as in studies on NSAID-induced gastric damage, the inhibition of COX-1 and COX-2 was needed in rats because COX- 2 might substitute COX-1 in producing cytoprotective prostaglandins. ${ }^{7,28}$

Prostaglandins have been identified to have a direct effect on osteoclast and osteoblast formations and activities while also maintaining the balance between bone resorption and bone formation. ${ }^{29,30,31} \mathrm{~A}$ study comparing $50 \%$ inhibitory concentration $\left(\mathrm{IC}_{50}\right)$ values in prostaglandin $E_{2}\left(P_{G}\right.$ ) production by a marker of monocyte COX-2 activity using bacterial lipopolysaccharide has identified that the $\mathrm{IC}_{50}$ for Paracetamol, Indomethacin (an aspirin-like drug) and Diclofenac are 1.6, 1.9 and 29, respectively ${ }^{32,33}$ The three types of NSAIDs, i.e. Paracetamol, Aspirin, and Diclofenac, have been known not to inhibit, partly inhibit, and totally inhibit OTM. ${ }^{11}$ Paracetamol inhibits both COX-1 and COX-2; therefore, a continued supply of paracetamol twice a day might stimulate OTM more however further studies are still needed.

Currently, no study has been conducted on $\mathrm{IC}_{50}$ of COX-1/COX2 of PGV-0 in comparison to paracetamol using bone cells. Nevertheless, the anti-inflammatory and analgesic activities of PGV-0 was found to be higher than those of paracetamol in vivo. The $\mathrm{IC}_{50}$ for COX showed that the $\mathrm{IC}_{50}$ for PGV-0 is higher than for curcumin. The antioxidant and anticyclo-oxygenase (anti-COX) activity of PGV- 0 is 2 and 7 times higher than curcumin while the anti-inflammatory activity is 5 times higher than curcumin at a same dose (20 $\mathrm{mg} / \mathrm{kg}$, per oral). ${ }^{34}$

A post-hoc test of one-way ANOVA intra days showed that on day 3 the OTM in ORT, Na-CMC, $\mathrm{PCT}$. and PGV- 0 groups was significantly higher in comparison with the OTM in NT but there were 
no differences in the amount of OTM between different experimental groups. On day 4, all groups had the same OTM as the NT group with no differences between groups. Starting from day 5 , all orthodontic groups showed an increase in the OTM distance with no differences between all orthodontic groups despite the observation that the maximum movement was achieved in PGV0 on day 7. Asefi et al. also found that injecting curcumin during OTM to rats does not lead to any inhibitory effect on OTM after 21 days but it inhibit root and bone resorption, osteoclastic recruitment, and angiogenesis significantly. ${ }^{34}$ The PGV-0 has been revealed as a selective COX-2 inhibitor ${ }^{35}$ that did not only impair the osteoclast but also osteoblast. However, further experiments are still needed.

To summarize, the results of this study showed that PGV-O and its positive control, paracetamol, did not inhibit OTM despite their action in inhibiting COX-2. There was a significant interaction between variable day and drugs and that the modulation of OTM was not only caused by the drugs but was also influenced by the force decay. PGV-0 could be developed as an analgesic of choice for patients under orthodontic therapy, but further studies are recommended.

\section{CONCLUSION}

After a single orthodontic force, PGV-0 does not inhibit tooth movement in rats from day 1 to day 7. Therefore, it is possible to develop PGV-0 as an alternative analgesics during orthodontic therapy.

\section{REFERENCES}

1. Mayahara K, Yamaguchi A, Takenouchi H, Kariya T, Taguchi H, Shimizu N. Osteoblasts stimulate osteoclastogenesis via RANKL expression more strongly than periodontal ligament cells do in response to PGE2. Arch Oral Biol. 2012; 57(10): 1377-84. DOI: 10.1016/j.archoralbio.2012.07.009.

2. Sodagar A, Etezadi T, Motahhary P, Dehpour AR, Vaziri H, Khojasteh A. The effect of celecoxib on orthodontic tooth movement and root resorption in rat. J Dent (Tehran). 2013; 10(4): 303-11.
3. Yang YQ, Li XT, Rabie AB, Fu MK, Zhang D. Human periodontal ligament cells express osteoblastic phenotypes under intermittent force loading in vitro. J Biol Chem. 2006; 281(10): 6448-54. DOI: 10.2741/1835

4. Salmassian R, Oesterle LJ, Shellhart WC, Newman SM. Comparison of the efficacy of ibuprofen and acetaminophen in controlling pain after orthodontic tooth movement. Am J Orthod Dentofac Orthop. 2009; 135(4): 51621. DOI: $10.1016 / j$.ajodo.2007.05.020.

5. Cottrell J, O'Connor JP. Effect of non-steroidal anti-inflammatory drugs on bone healing. Pharmaceuticals (Basel). 2010; 3(5): 1668-93. DOI: $10.3390 / \mathrm{ph} 3051668$.

6. Araujo AS, Fernandes ABN, Maciel JVB, Netto $J$ de NS, Bolognese AM. New methodology for evaluating osteoclastic activity induced by orthodontic load. J Appl Oral Sci. 2015; 23(1): 19-25. DOI: $10.1590 / 1678-775720140351$.

7. Lee W. Experimental study of the effect of prostaglandin administration on tooth movement-With particular emphasis on the relationship to the method of PGE1 administration. Am J Orthod Dentofac Orthop. 1990; 98(3): 231-41. DOI: 10.1016/s08895406(05)81600-2.

8. Warner TD, Mitchell JA. Cyclooxygenase-3 (COX-3): Filling in the gaps toward a COX continuum. Proc Natl Acad Sci. 2002; 99(21): 13371-3. DOI: $10.1073 /$ pnas.222543099.

9. Sari E, Olmez H, Gurton AU. Comparison of some effects of acetylsalicylic acid and rofecoxib during orthodontic tooth movement. Am J Orthod Dentofac Orthop. 2004; 125(3): 310-5. DOI: 10.1016/S0889540603009144.

10. Meeran NA. Biological response at the cellular level within the periodontal ligament on application of orthodontic force-An update. J Orthod Sci. 2012; 1(1): 2-10. DOI: 10.4103/2278-0203.94769.

11. Arias OR, Marquez-Orozco MC. Aspirin, acetaminophen, and ibuprofen: Their effects on orthodontic tooth movement. Am J Orthod Dentofac Orthop. 2006; 130(3): 364-70. DOI: 10.1016/j.ajodo.2004.12.027.

12. Kaur H, Bansal N, Abraham R. A randomized, single-blind, placebo-controlled trial to evaluate the effectiveness of verbal 
behavior modification and acetaminophen on orthodontic pain. Angle Orthod. 2019; 89(4): 617-23. DOI: $10.2319 / 080518-570.1$

13. Paul AD, Chauhan CK. Study of usage pattern of nonsteroidal anti-inflammatory drugs (NSAIDs) among different practice categories in Indian clinical setting. Eur J Clin Pharmacol. 2005; 60(12): 889-92. DOI: 10.1007/s00228-0040849-6.

14. Reksohadiprodjo MS, Timmerman $\mathrm{H}$, inventors; Universitas Gadja Mada, assignee. Derivatives of benzilidine cyclohexanone, benzilidine cyclopentanone, and benzilidine acetone and their synthesis. United States patent US 6,541,672. 2003 Apr 1.

15. Anand P, Thomas SG, Kunnumakkara AB, Sundaram C, Harikumar KB, Sung B. Biological activities of curcumin and its analogues (Congeners) made by man and Mother Nature. Biochem Pharmacol. 2008; 76(11): 1590-611. DOI: $10.1016 /$ j.bcp. 2008.08.008.

16. Ritmaleni. Synthesis of pentagamavunon-0 (PGV-0): An improved technique. Int J Pharm Sci Rev Res. 2016; 39(1): 9-11.

17. DewiWR. Analgesic Effect of Pentagamavunon-0 (PGV-0) in Female DDY mice [minor thesis]. Yogyakarta: Gadjah Mada University; 2003.

18. Nurrochmad A, Margono SA, Sardjiman, Hakim AR, Ernawati, Kurniawati E. Hepatoprotective and antioxidant activity of pentagamavunon- 0 against carbon tetrachloride-induced hepatic injury in rats. Asian Pac J Trop Med. 2013; 6(6): 438-42. DOI: 10.1016/S1995-7645(13)60070-X.

19. Keles A, Grunes B, Difuria C, Gagari E, Srinivasan V, Darendeliler MA. Inhibition of tooth movement by osteoprotegerin vs pamidronate under conditions of constant orthodontic force. Eur J Oral Sci. 2007; 131-6. DOI: $10.1111 / j .1600-0722.2007 .00433 . x$

20. Van Leeuwen EJ, Maltha JC, Kuijpers-Jagtman AM. Tooth movement with light continuous and discontinuous forces in beagle dogs. Eur J Oral Sci. 1999; 107(6): 468-74. DOI: 10.1111/j.1600-0722.2007.00433.x.

21. Von Bohl M, Maltha JC, Von Den Hoff JW, Kuijpers-Jagtman AM. Focal hyalinization during experimental tooth movement in beagle dogs. Am J Orthod Dentofac Orthop. 2004; 125(5): 615-23. DOI: 10.1016/j. ajodo.2003.08.023
22. Von Böhl M, Maltha J, Von Den Hoff H, KuijpersJagtman $A M$. Changes in the periodontal ligament after experimental tooth movement using high and low continuous forces in beagle dogs. Angle Orthod. 2004; 74(1): 16-25. DOI: 10.1043/0003-3219(2004)074<0016:CITPLA $>2$.

23. Pilon JJ, Kuijpers-Jagtman AM, Maltha JC. Magnitude of orthodontic forces and rate of bodily tooth movement: An experimental study. Am J Orthod Dentofacial Orthop. 1996; 110(1): 16-23. DOI: 10.1016/s0889$\underline{5406(96) 70082-3}$

24. Von BöhlM, Kuijpers-Jagtman AM. Hyalinization during orthodontic tooth movement: a systematic review on tissue reactions. Eur $\mathrm{J}$ Orthod. 2009; 31(1): 30-6. DOI: 10.1093/ejo/ cjn080

25. Shetty N, Patil AK, Ganeshkar SV, Hegde S. Comparison of the effects of ibuprofen and acetaminophen on PGE2 levels in the GCF during orthodontic tooth movement: A human study. Prog Orthod. 2013; 14(1): 1-5.

26. Kotake S, Yago T, Kawamoto M, Nanke Y. Effects of NSAIDs on differentiation and function of human and murine osteoclasts - Crucial "Human Osteoclastology." Pharmaceuticals (Basel). 2010; 3(5): 1394-410.

27. Williams LJ, Pasco JA, Henry MJ, Sanders KM, Nicholson GC, Kotowicz MA, et al. Paracetamol (acetaminophen) use, fracture and bone mineral density. Bone. 2011;48(6):1277-81.

28. Wallace JL, McKnight W, Reuter BK, Vergnolle N. NSAID-Induced gastric damage in rats: Requirement for inhibition of both cyclooxygenase 1 and 2. Gastroenterology. 2000;119(3):706-14.

29. Lin CH, Jee WSS, Ma YF, Setterberg RB. Early effects of prostaglandin E2 on bone formation and resorption in different bone sites of rats. Bone. 1995 Oct;17(4 Suppl):255S-259S. DOI: 10.1016/8756-3282(95)00300-3

30. Nefussi JR, Baron R. PGE2 stimulates both resorption and formation of bone in vitro: Differential responses of the periosteum and the endosteum in fetal rat long bone cultures. Anat Rec. 1985;211(1):9-16.

31. Kawaguchi H, Pilbeam CC, Harrison JR, Raisz LG. The role of prostaglandins in the regulation of bone metabolism. Clin Orthop Rel Res. 1995;(313):36-46. 
32. Patrignani P, Panara MR, Greco A, Fusco O, Natoli $C$, lacobelli $S$, et al. Biochemical and pharmacological characterization of the cyclooxygenase activity of human blood prostaglandin endoperoxide synthases. J Pharmacol Exp Ther. 1994;271(3):1705-12.

33. Baigent C, Patrono C. Selective cyclooxygenase 2 inhibitors, aspirin, and cardiovascular disease: A reappraisal. Arthritis Rheum. 2003;48(1):12-20.

34. Sardjiman. Synthesis of some new series of curcumin analouges, anti-oxidative, antiinflammatory, anti-bacterial acitivities and qualitative structure-activity-relationship, Disertation, 2000, Universitas Gadjah Mada

35. Asefi S, Seifi M, Fard G, Lotfi A. Innovative evaluation of local injective gel of curcumin on the orthodontic tooth movement in rats. Dent Res J (Isfahan). 2018;15(1):40.

36. Adhyatmika A, Ronny M, Hilda I, Nanoparticle Preparation of Pentagamavunon-0 Using Medium Viscous Chitosan Matrix Cross Linked by Sodium Tripolyphosphate Through Ionic Gelation Mechanism as Anti-Inflammatory Candidate. Majalah Farmaseutik. 2017;13(2):65-7 